\title{
Analysis of Functional Groups of Porphyrins by Collision-Induced Dissociation Mass Spectrometry/Mass Spectrometry
}

\author{
Toshimichi Shibue*, Hisashi KaMbE*, Hiroyuki Nishide** and Yoko OHASHI*** \\ *Materials Characterization Central Laboratory, School of Science and Engineering, Waseda University, \\ Shinjuku, Tokyo 169, Japan \\ ** Department of Applied Chemistry, School of Science and Engineering, Waseda University, \\ Shinjuku, Tokyo 169, Japan \\ ***Institute of Physical and Chemical Research (RIKEN), Wako, Saitama 351-01, Japan
}

\begin{abstract}
Collision-induced dissociation mass spectrometry/mass spectrometry (CID-MS/MS) was effective for estimating the substituent groups of porphyrin. The substituents of the porphyrin plane, which form the pathway for an oxygenbinding reaction, are essential for its oxygen-binding affinity. The CID-MS/MS of 5,10,15-tris(o-pivalamidophenyl)monoaminoporphyrinatocobalt and 5,10,15,20-tetrakis(o-pivalamidophenyl)porphyrinatocopper was measured, and their fragmentations were studied using $B / E$-constant and $B(1-E)^{1 / 2} / E$-constant linked-scan techniques. These CIDMS/MS spectra clearly show that the substituent group represents the eliminations of the alkyl and acyl radicals from the molecular ions. Thus, the CID-MS/MS technique has been proven to be useful for characterizing porphyrin substituents.
\end{abstract}

Keywords Porphyrin, mass spectrometry, collision-induced dissociation mass spectrometry/mass spectrometry, $B / E-$ constant linked-scan, $B(1-E)^{1 / 2} / E$-constant linked-scan

A number of porphyrin derivatives with specific and reversible oxygen-binding abilities have been synthesized by mimicking hemoglobin and myoglobin. The oxygenbinding affinity of these porphyrins are strongly dependent on the species of the central metals, the base ligands at the fifth site, the porphyrin structure, and the surrounding environment. The substituents of the porphyrin plane, which form the pathway for the oxygenbinding reaction, affect the oxygen-binding affinity. ${ }^{1,2}$

An analysis of the structure of the functional groups of the porphyrins is generally carried out by infrared (IR) and (NMR) spectroscopy. There are difficulties, however, in the structural studies of porphyrins by IR and NMR spectrometry: NMR spectrometry requires a large sample size $(0.1 \mathrm{mg})$, and IR spectrometry cannot distinguish between a substituent group in number, that is, whether there are three substitution sites or four. The technique of collision-induced dissociation mass spectrometry/mass spectrometry (CID-MS/MS) with the linked-scan techniques has been reported by many researchers. ${ }^{3-10}$ However, there has been no report concerning analyses of the structure of the functional groups of the porphyrins.

In order to obtain information about the substituent functional groups of the porphyrin plane, the losses from the porphyrin molecular ions were analyzed by CIDMS/MS with the linked-scan techniques for cases in which the substituent groups were identical.

\section{Experimental}

All of the chemicals used were commercial of analytical grade, and were used without further purification.

5,10,15-tris (o-pivalamidophenyl)monoaminoporphyrinatocobalt and 5,10,15,20-tetrakis(o-pivalamidophenyl)porphyrinatocopper were prepared according to a procedure of Collman et al. ${ }^{11}$ Figure 1 shows the chemical structures of these compounds. Figures 2 and 3 show the EIMS spectra of 5,10,15-tris(o-pivalamidophenyl)monoaminoporphyrinatocobalt and 5,10,15,20-tetrakis( $o$ pivalamidophenyl)porphyrinatocopper.

All of the experiments were performed using a doublefocusing reversed-geometry mass spectrometer (JEOL JMS-SX102A).

The magnetic and electric fields were calibrated against Perfluorokerosene Super-high boiling (Tokyo Kasei Kogyo Co).

The electron ionization (EI) conditions were as follows: ionizing voltage, $70 \mathrm{~V}$; ion source temperature, $250^{\circ} \mathrm{C}$; ion acceleration voltage, $10 \mathrm{kV}$; post acceleration detector voltage, $10 \mathrm{kV}$. Direct inlet system was used. The mass spectrometer was equipped with a data system (JMS-complement), and full mass spectra $(0-2000 \mathrm{u})$ were recorded every $10 \mathrm{~s}$. 5,10,15-Tris(o-pivalamidophenyl)monoaminoporphyrinatocobalt and $5,10,15,20-$ tetrakis(o-pivalamidophenyl)porphyrinatocopper, re- 

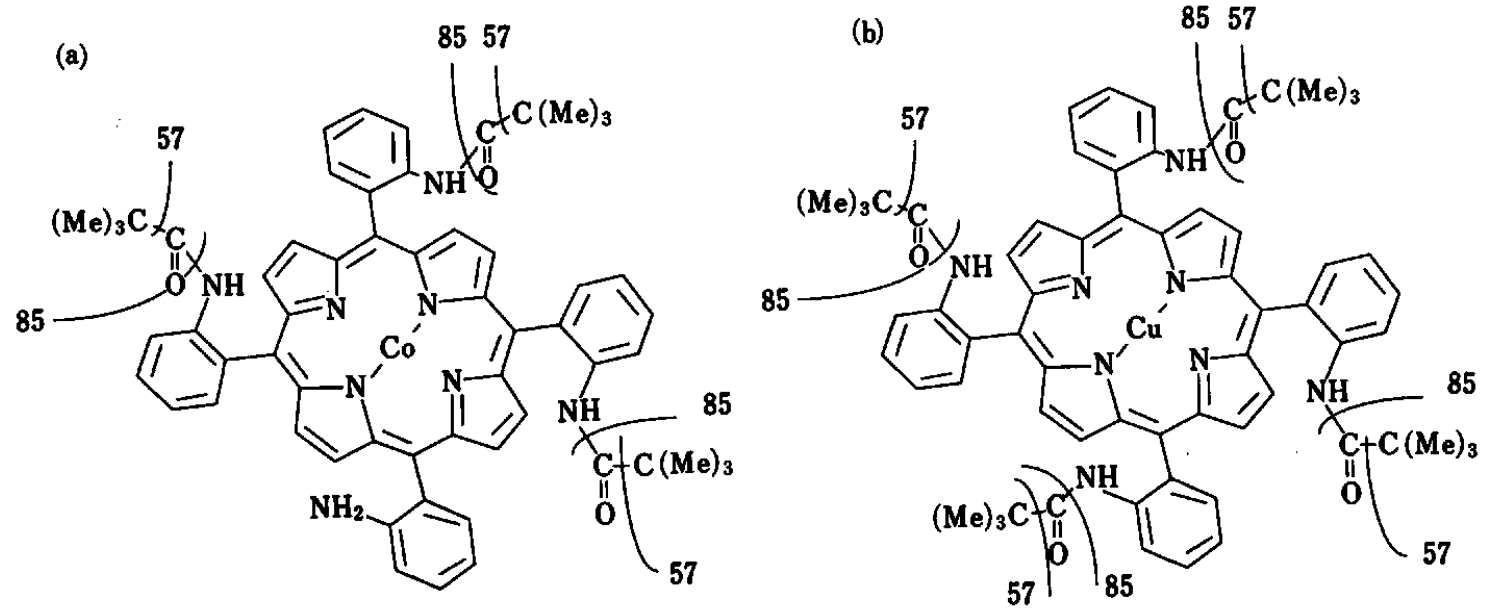

Fig. 1 Chemical structures of 5,10,15-tris(o-pivalamidophenyl)monoaminoporphyrinatocobalt (a) and 5,10,15,20-tetrakis(o-pivalamidophenyl)porphyrinatocopper (b).

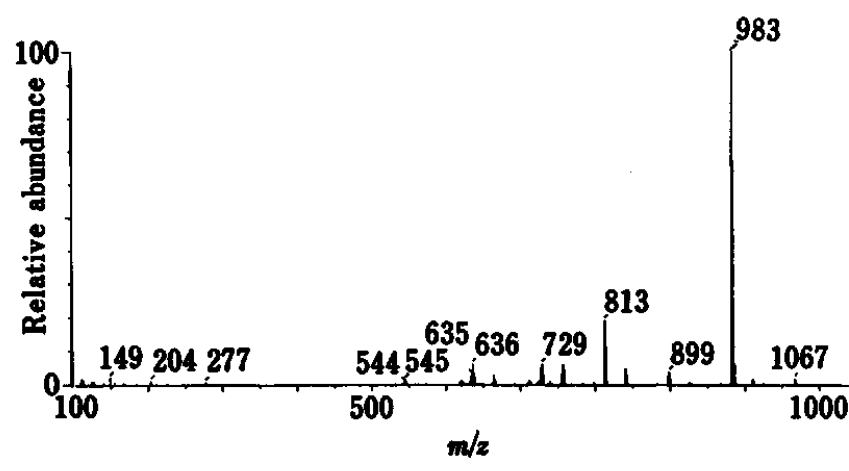

Fig. 2 EIMS spectrum of the 5,10,15-tris(o-pivalamidophenyl)monoaminoporphyrinatocobalt.

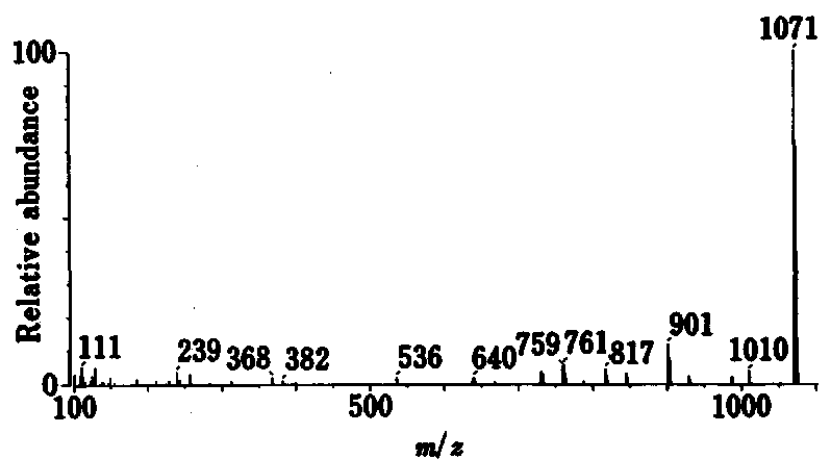

Fig. 3 EIMS spectrum of 5,10,15,20-tetrakis(o-pivalamidophenyl)porphyrinatocopper.

spectively, were applied directly to the sample holder of the direct inlet system. The temperature of the sample holder was raised to $480^{\circ} \mathrm{C}$ according to the program. Molecular ions were selected as precursor ions for CIDMS/MS studies. Helium gas was introduced in order untill the intensity of the molecular ions was decreased to
$50 \%$, and the $B / E$-constant linked-scans and $B(1-E)^{1 / 2} /$ $E$-constant linked-scans were recorded.

\section{Results and Discussion}

CID-B/E-constant linked-scan spectrum of the 5,10,15tris(o-pivalamidophenyl)monoaminoporphyrinatocobalt of molecular ion $(m / z 983)$ produced product ions at $m /$ $z 898,841,813,756$ and 728 . The spectrum is shown in Fig. 4.

Figure 5 shows the CID- $B(1-E)^{1 / 2} / E$-constant linkedscan spectrum (neutral loss of $85 \mathrm{u}$ ) of 5,10,15-tris (opivalamidophenyl)monoaminoporphyrinatocobalt. The neutral loss spectrum (Fig. 5) shows that a neutral species of $85 \mathrm{u}$, corresponding to the $\mathrm{C}_{5} \mathrm{H}_{9} \mathrm{O}$ radical, is eliminated not only from the molecular ion $(m / z 983)$, but also from the fragment ions at $m / z 898$ and 813 , giving product ions at $m / z 898$ and 813 , respectively. The absence of fragment ions at $m / z 756$, which are present in Fig. 4, indicates that the elimination of $\mathrm{C}_{5} \mathrm{H}_{9} \mathrm{O}$ also occurs from the ion at $m / z 841$, which is possibly derived from an other series of fragmentation.

Figure 6 shows the CID- $B(1-E)^{1 / 2} / E$-constant linkedscan spectrum (neutral loss of $57 \mathrm{u}$ ) of 5,10,15-tris(o-pivalamidophenyl)monoaminoporphyrinatocobalt. Based on these spectral data (Figs. 4-6), the presence of three amidophenyl groups (pivaloyl $\mathrm{C}_{5} \mathrm{H}_{9} \mathrm{O} 85 \mathrm{u}$ ) is concluded. Similarly, the CID-B/E-constant linked-scan spectrum of the 5,10,15,20-tetrakis(o-pivalamidophenyl)porphyrinatocopper of molecular ion $(\mathrm{m} / \mathrm{z} 1071)$ produced product ions at $m / z 986,929,901,844,816,759$ and 731, which indicates, again, a series of eliminations of $\mathrm{C}_{5} \mathrm{H}_{9} \mathrm{O}$ (Fig. 7).

Figure 8 shows the CID- $B(1-E)^{1 / 2} / E$-constant linkedscan spectrum (neutral loss, $85 \mathrm{u}$ ) of 5,10,15,20-tetrakis(o-pivalamidophenyl)porphyrinatocopper. Figure 9 shows the CID- $B(1-E)^{1 / 2} / E$-constant linked-scan spec- 


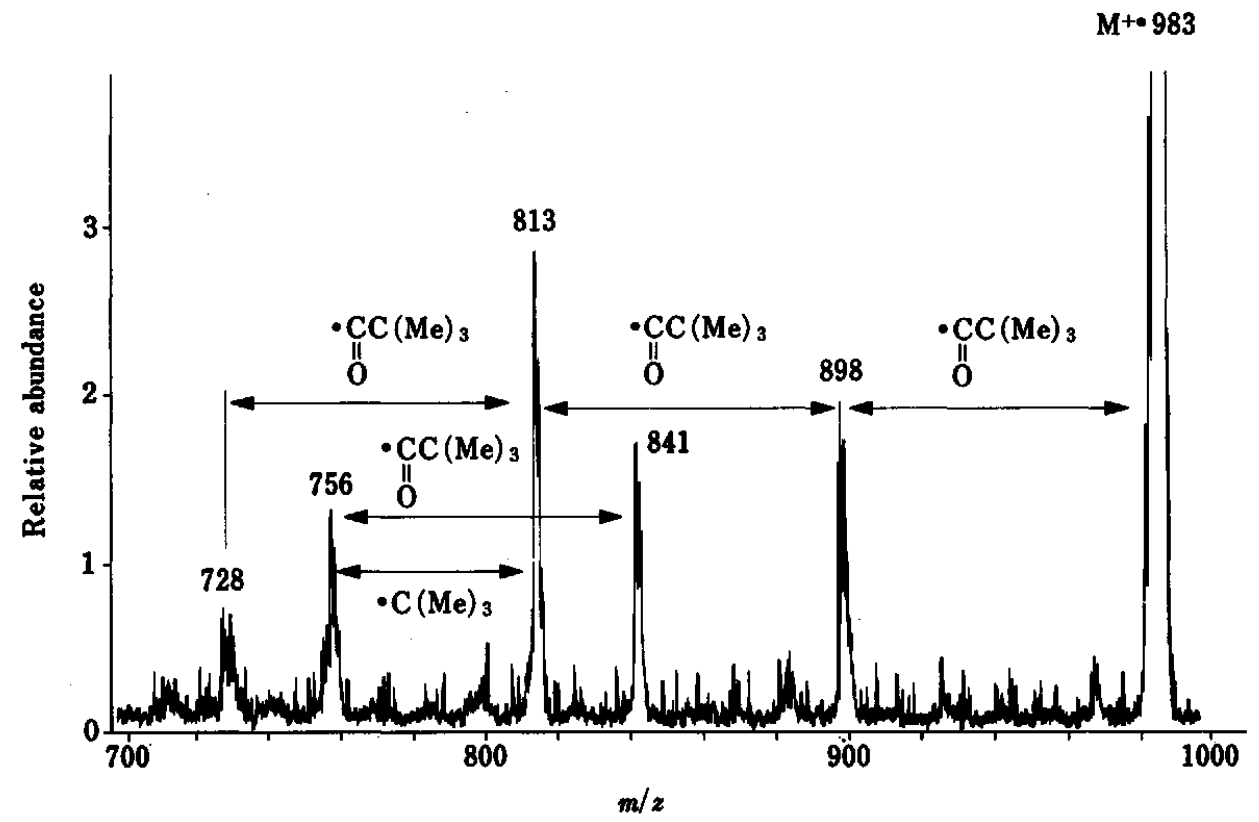

Fig. 4 Collision-induced dissociation $B / E$-constant linked-scan spectrum of the $5,10,15$-tris(o-pivalamidophenyl)monoaminoporphyrinatocobalt of molecular ion $(m / z$ 983).

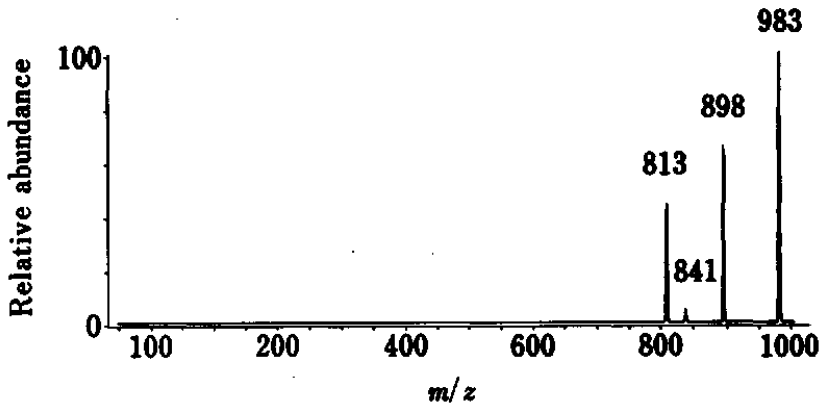

Fig. 5 Collision-induced dissociation $B(1-E)^{1 / 2} / E$-constant linked-scan spectrum (neutral loss of $85 \mathrm{u})$ of 5,10,15-tris $(O$ pivalamidophenyl)monoaminoporphyrinatocobalt.

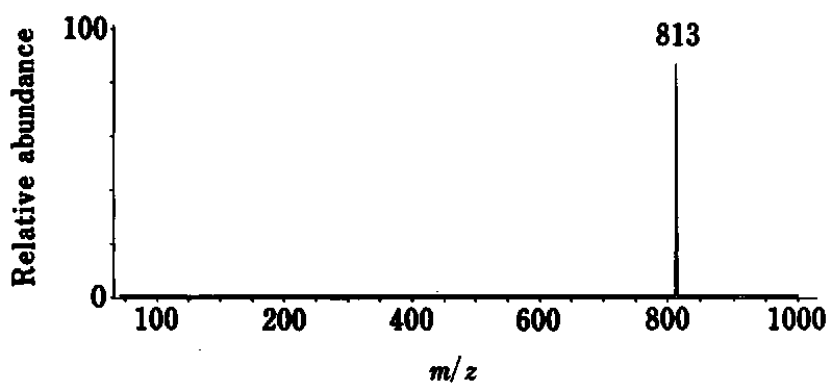

Fig. 6 Collision-induced dissociation $B(1-E)^{1 / 2} / E$-constant linked-scan spectrum (neutral loss of $57 \mathrm{u}$ ) of 5,10,15-tris $(o-$ pivalamidophenyl)monoaminoporphyrinatocobalt. trum (neutral loss $57 \mathrm{u}$ ) of 5,10,15,20-tetrakis(o-pivalamidophenyl)porphyrinatocopper. Based on these spectral data (Figs. 7-9), the presence of the four amidophenyl groups (pivaloyl $\mathrm{C}_{5} \mathrm{H}_{9} \mathrm{O} 85 \mathrm{u}$ ) is elucidated.

In conclusion, collision-induced dissociation mass spectrometry/mass spectrometry (CID-MS/MS) is useful for analyzing the modification structures of porphyrins.

Presented in part at the 69th Annual Meeting of the Chemical Society of Japan, Kyoto, March 1995, Abstracts, p. 149.

\section{References}

1. E. Tsuchida and H. Nishide, Top. Curr. Chem., 132, 63 (1986).

2. H. Nishide and T. Suzuki, Porphyrins, 2, 129 (1993).

3. H. Nakata, N. Yamaoka and K. Kadoguchi, J. Mass Spectrom. Soc. Jpn., 42, 155 (1994).

4. M. Yamamoto, M. Tanaka, Y. Yokota and T. Takeuchi, J. Mass Spectrom. Soc. Jpn., 41, 277 (1993).

5. N. Senda, H. Wakayama, T. Fujita, T. Bando, K. Shizukuishi, H. Yamaoka and M. Nakayama, J. Mass Spectrom. Soc. Jpn., 42, 325 (1994).

6. T. Takeuchi, N. Higuchi, K. Iida, M. Yamamoto, T. Matsushita and K. Nishimoto, J. Mass Spectrom. Soc. Jpn., 42, 277 (1994).

7. F. Nishida, K. Matsuda, K. Harada, M. Suzuki, V. Meevootisom, T. W. Flegel, Y. Thebtaranonth and S. Intararuangsorn, J. Mass Spectrom. Soc. Jpn., 43, 27 (1995).

8. F. Nishida, K. Harada, M. Suzuki, T. Fujita, H. Naoki, V. Meevootisom, T. W. Flegel, Y. Thebtaranonth and S. 


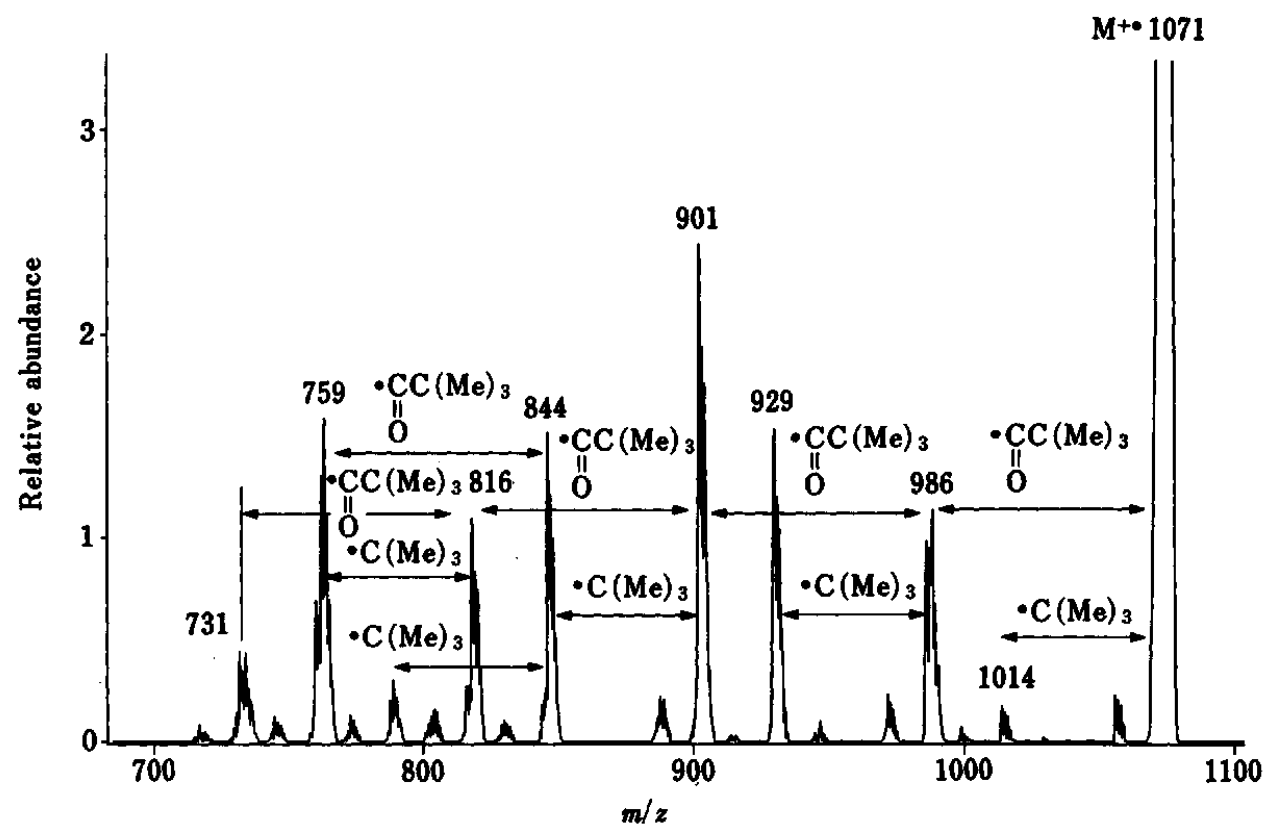

Fig. 7 Collision-induced dissociation $B / E$-constant linked-scan spectrum of the $5,10,15,20$-tetrakis (o-pivalamidophenyl)porphyrinatocopper of molecular ion $(m / z$ 1071).

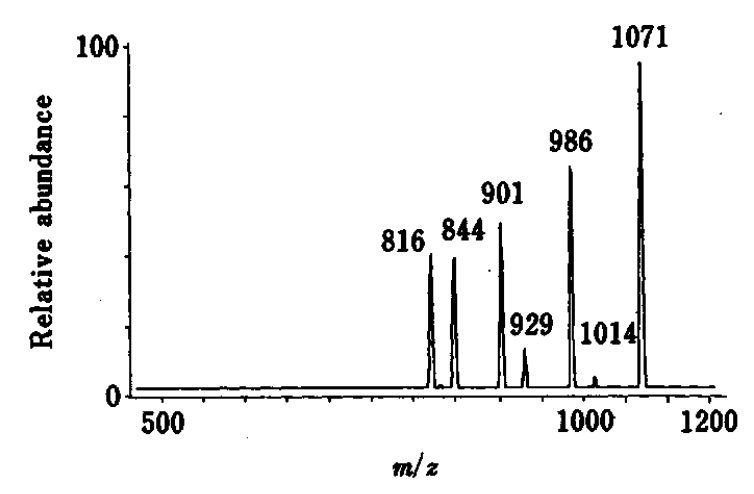

Fig. 8 Collision-induced dissociation $B(1-E)^{1 / 2} / E$-constant linked-scan spectrum (neutral loss of $85 \mathrm{u}$ ) of $5,10,15,20$ tetrakis(o-pivalamidophenyl)porphyrinatocopper.

Intararuangsorn, J. Mass Spectrom. Soc. Jpn., 43, 37 (1995).

9. N. Senda, Y. Kubota, T. Hoshino, H. Nozaki, H. Hayashi and M. Nakayama, J. Mass Spectrom. Soc. Jpn., 43, 45 (1995).

10. T. Takeuchi , N. Murata, Y. Yokota, Y. Kyoya, K. Iwai and M. Yamamoto, J. Mass Spectrom. Soc. Jpn., 43, 53 (1995).

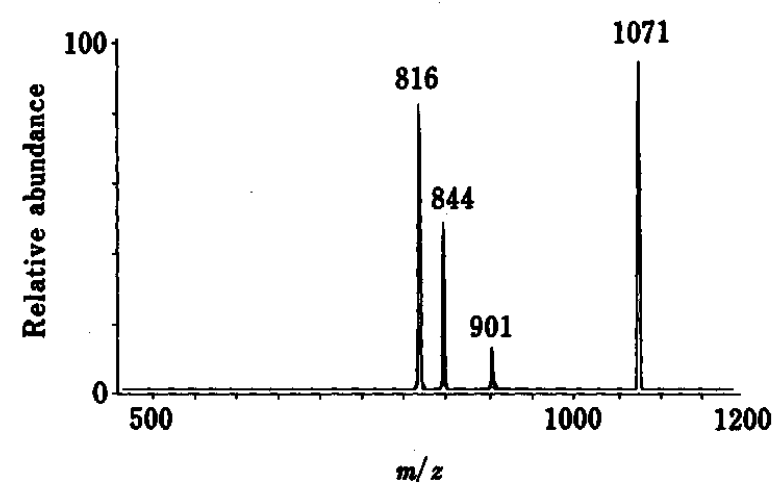

Fig. 9 Collision-induced dissociation $B(1-E)^{1 / 2} / E$-constant linked-scan spectrum (neutral loss of $57 \mathrm{u}$ ) of $5,10,15,20$ tetrakis(o-pivalamidophenyl)porphyrinatocopper.

11. J. P. Collman, R. R. Gagne, C. A. Reed, T. R: Halbert, G. Lang and W. T. Robinson, J. Am. Chem. Soc., 97, 1427 (1975)

(Received July 5, 1995) (Accepted August 24, 1995) 